\title{
Prevalence and socioeconomic correlates of unintented pregnancy among women in rural Bangladesh
}

\author{
Mostafa Kamal, MSc, PhD, ${ }^{(1)}$ Aynul Islam, MSc, PhD. ${ }^{(2)}$
}

\begin{abstract}
Kamal M, Islam A. Prevalence and socioeconomic correlates of unintented pregnancy among women in rural Bangladesh. Salud Publica Mex 201 I;53:108-I I5.
\end{abstract}

\begin{abstract}
Objective. This paper examines the prevalence and socioeconomic correlates of unintended pregnancy among rural women in Bangladesh. Material and Methods. The study used data from the 2007 Bangladesh Demographic and Health Survey. Chi-square tests and binary logistic regression were performed using the data set. Results. Overall, $30.0 \%$ of the most recent births were unplanned. Both bivariate and multivariate analyses confirm that age, ever use of contraceptive method, religion and wealth index were important determinants of unintended pregnancy. Pregnancy order appeared as the most single determinant of unplanned pregnancy. Women with fourth or higher order pregnancies were at higher risk $(\mathrm{OR}=4.3 \mathrm{I}, 95 \% \mathrm{Cl} ; 4.3 \mathrm{I}-6.56)$ of unintended pregnancy than those who experienced pregnancy for the first time. Conclusion. Unintended pregnancy is common in rural Bangladesh. Intervention programs regarding reproductive health and services should be undertaken.Awareness should be created to continue the use of modern contraceptive methods to avoid unintended pregnancy.
\end{abstract}

Key words: logistic regression; rural; pregnancy; women; Bangladesh
Kamal M, Islam A.

Prevalencia y factores socioeconómicos asociados

a embarazos no deseados en mujeres

de áreas rurales de Bangladesh.

Salud Publica Mex 201 I;53:108-I 15.

\section{Resumen}

Objetivo. Este artículo evalúa la prevalencia y los factores socioeconómicos asociados a embarazos no deseados en mujeres de áreas rurales de Bangladesh. Material y métodos. Para este estudio empleamos la Encuesta Demográfica y de Salud de Bangladesh de 2007. Para el análisis de los datos se usó la ji cuadrada y regresión logística. Resultados. Treinta por ciento de los embarazos más recientes no fueron planificados. Los análisis bivariados y multivariados confirmaron que la edad, el usar alguna vez anticonceptivos, la religión y el índice de riqueza fueron determinantes importantes de los embarazos no deseados. El orden de la gestación fue el factor único más determinante de tener un embarazo no deseado. Las mujeres con cuatro o más embarazos tuvieron mayor riesgo ( $R M=4.3 \mathrm{I}$, IC $95 \%=4.3 \mathrm{I}-6.56)$ de embarazos no deseados que aquellas que estuvieron gestando por primera vez. Conclusión. Los embarazos no deseados son comunes en áreas rurales de Bangladesh. Para evitar embarazos no deseados deberían ser implementados programas de intervención enfocados en servicios de salud reproductiva y se debería incrementar el conocimiento sobre el uso de métodos modernos de anticoncepción.

Palabras clave: regresión logística; rural; embarazos no deseados; mujeres; Bangladesh

(I) Department of Mathematics, Islamic University. Kushtia, Bangladesh.

(2) Department of Economics, Islamic University. Kushtia, Bangladesh.

Received on: August 18,2010 - Accepted on: January 14, 201 I

Address reprint requests to: Mostafa Kamal, MSc, PhD. Department of Mathematics, Islamic University. Kushtia-7003, Bangladesh E-mail:kamaliubd@yahoo.com 
A $\mathrm{n}$ unintended pregnancy is a pregnancy that is either mistimed (occurred earlier than the desired time) or unwanted (occurred when no more children were desired) at the time of conception. ${ }^{1}$ Worldwide, of the 210 million pregnancies occurring each year, nearly 80 million are unintended. ${ }^{2}$ Women who did not intend to become pregnant often resorted to an abortion, typically carried out beyond the reach of health services or providers. $^{3}$

Unintended pregnancy poses hardships for families and jeopardizes the health of millions of women and children. ${ }^{4}$ It is, thus, an important social and public health concern. ${ }^{5}$ It increases the risk of abortion-related morbidity and mortality, ${ }^{6}$ especially in countries where abortion is illegal. ${ }^{7}$ In fact, unsafe abortion is one of the common results of unintended pregnancy, from which 80000 women die each year and over $95 \%$ of these deaths occur in developing countries. ${ }^{8}$ Researches also argue that unplanned pregnancy leads to adverse mental health consequences ${ }^{9,10}$ and has adverse impacts on antenatal care, breastfeeding and infant mortality. ${ }^{11,12}$

Bangladesh has shown remarkable progress in fertility decline, from a high level of 6.3 births per woman in the mid-1970s to 2.7 births per woman in 2007; there has also been a sharp increase in the contraceptive prevalence rate, from $7.7 \%$ to $55.8 \%$ during the same period. In 2007, only 1.9 births per woman were wanted, indicating that 0.8 births per woman were unwanted..$^{13}$ In Bangladesh, maternal mortality is still high -one of the highest in South Asia- with 322 per 100000 live births. ${ }^{14}$ Of these deaths, abortion ${ }^{15}$ accounted for roughly $13.0 \%$, although not all these deaths are solely attributed to unintended pregnancy.

The level of unintended pregnancy serves as an indicator of women's ability to control fertility, the state of women's health and their degree of autonomy. Unintended pregnancies are a consequence of multiple factors, including non-use of contraception. ${ }^{16} \mathrm{How}-$ ever, even in countries with a low desired family size and higher use of contraceptive methods, unintended pregnancies are still common due to contraceptive failure and discontinuation. ${ }^{17,18}$ Despite a sharp increase in contraceptive use, many Bangladeshi women still experience unintended pregnancy, and a complex set of social and psychological factors leads women to be at risk. While many researchers worldwide have investigated the prevalence and factors associated with unintended pregnancy, little is known about this subject in relation to rural Bangladesh. Therefore, this paper aims to explore the prevalence and socioeconomic correlates of unintended pregnancy among rural women in Bangladesh.

\section{Material and Methods}

\section{Data}

The study used data from the nationally representative 2007 Bangladesh Demographic and Health Survey (BDHS). The survey used a multistage cluster sampling procedure to gather information from a weighted sample of 10996 ever married women from the six administrative divisions in the country. The survey obtained detailed information on fertility, marriage, fertility preference and intention, awareness and use of family planning methods, childhood mortality, and maternal and child health, among others. It followed all the protocols prescribed by the World Health Organization (WHO). A written consent was obtained from all the respondents prior to starting the interview. The sample was weighted by the weighting factor provided in the survey data. Of the respondents, 3866 rural women had at least one live birth during the five years preceding the survey; they are the basis of the study. The details of the survey are described elsewhere. ${ }^{13}$

\section{Dependent variable}

The outcome variable of this study is the "intention status of the most recent live birth in the five years preceding the survey date." This was determined by asking women, "Did you want your last child?" The responses to this question were: "wanted then," "wanted later" and "wanted no more" (unwanted). The latter two were merged as "unintended" to make the variable binary. In this study, as in other studies, 5,19 some women are assumed to state that an "unintended" pregnancy had been "intended" and vice versa due to memory collapse.

\section{Independent variables}

A set of ten potential variables were considered as the independent variables, namely women's age group (1519, 20-24, 25-29, 30-34, 35-39, 40-49), maternal education (no formal education, primary and secondary or higher), age at first marriage ( $<18$ years and 18 years or older), religion (Islam and others), pregnancy order (first, second, third and fourth or higher), inter-spousal communication about family planning (FP), administrative regions (Barisal, Chittagong, Dhaka, Khulna, Rajshahi and Sylhet), wealth index (poorest, poor, middle, richer and richest), ever use of FP method (never used, used only traditional and used only modern method), and current use status of FP methods (not using, using traditional method and using modern method). 


\section{Analytical approach}

Both bivariate and multivariate statistical analyses were employed in this study. After performing chisquare tests to examine the association between the dependent and independent variables, binary logistic regression models were constructed to examine the net effects of the independent variables on unintended pregnancy. Prior to performing the statistical analyses, multi-colinearity was tested. Age and pregnancy order were shown to have co-linearity. To avoid this co-linearity two separate logistic regression models were constructed. Model I was constructed by including age and other selected independent variables, except for pregnancy order, while in model II age was replaced by pregnancy order. To check for significant interaction effects among the explanatory variables, we tested major interaction terms between age, regions and wealth; however, they were not statistically significant. Therefore, the models constructed without interaction terms are the mostly parsimonious models, which provide the best estimations of the effects of the explanatory variables. The statistical analyses in this study were analyzed using SPSS v17.

\section{Results}

\section{Profile of the respondents}

Table I shows the background characteristics of the respondents. The mean age, age at marriage, and mean number of children ever born were $25.5 \pm 6.4$ years,

Table I

FREQUENCY DISTRIBUTION OF WOMEN WHO HAD AT LEAST ONE LIVE BIRTH IN THE FIVE YEARS PRECEDING THE SURVEY, BY BACKGROUND CHARACTERISTICS, BDHS, 2007 ( $N=3$ 866)

\begin{tabular}{|c|c|c|}
\hline & $N$ & $\%$ \\
\hline \multicolumn{3}{|c|}{ Current age } \\
\hline $15-19^{\circ}$ & 670 & 17.3 \\
\hline $20-24$ & $129 \mid$ & 33.4 \\
\hline $25-29$ & 942 & 24.4 \\
\hline $30-34$ & 548 & 14.2 \\
\hline $35-39$ & 288 & 7.5 \\
\hline $40-49$ & 127 & 3.3 \\
\hline
\end{tabular}

Maternal education

\begin{tabular}{lll} 
No education & 1079 & 27.9 \\
\hline Primary & 1221 & 31.6 \\
\hline Secondary or more & 1566 & 40.5
\end{tabular}

Age at marriage

\begin{tabular}{lrr}
$\begin{array}{l}<18 \text { years } \\
\text { I8 or more years }\end{array}$ & 3234 & 83.7 \\
$\begin{array}{l}\text { Religion } \\
\text { Islam }\end{array}$ & 632 & 16.3 \\
\hline Others & & \\
& 3528 & 91.3 \\
\hline & 338 & 8.7
\end{tabular}

\begin{tabular}{lrr}
$\begin{array}{l}\text { Birth order } \\
\text { First }\end{array}$ & 1218 & 31.5 \\
\hline Second & 990 & 25.6 \\
\hline Third & 649 & 16.8 \\
\hline Fourth or more & 1009 & 26.1 \\
$\begin{array}{l}\text { Discussed family planing* } \\
\text { No }\end{array}$ & & \\
\hline Yes & 1812 & 48.0 \\
\hline & 1965 & 52.0
\end{tabular}

\begin{tabular}{lrr}
$\quad$ Characteristics & $N$ & $\%$ \\
$\begin{array}{lrr}\text { Administrative regions } \\
\text { Barisal }\end{array}$ & 270 & 7.0 \\
\hline Chittagong & 803 & 20.8 \\
\hline Dhaka & 1080 & 27.9 \\
\hline Khulna & 406 & 10.5 \\
\hline Rajshahi & 964 & 24.9 \\
\hline Sylhet & 343 & 8.9 \\
Wealth index & & \\
Poorest & & \\
\hline Poor & 1005 & 26.0 \\
\hline Middle & 955 & 24.7 \\
\hline Richer & 809 & 20.9 \\
\hline Richest & 760 & 19.6 \\
\hline
\end{tabular}

Ever used family planning method

\begin{tabular}{lrr} 
No & 644 & 16.7 \\
\hline Only traditional & 142 & 3.7 \\
\hline Only modern & 3080 & 79.7
\end{tabular}

Currently using family planning method

\begin{tabular}{lrr} 
No & 1712 & 44.3 \\
\hline Only traditional & 243 & 6.3 \\
\hline Only modern & 1911 & 49.4
\end{tabular}

\begin{tabular}{lrr}
$\begin{array}{l}\text { Pregnancy intention status } \\
\text { Planned }\end{array}$ & 2705 & 70.0 \\
\hline Mistimed & 553 & 14.3 \\
\hline Unwanted & 606 & 15.7
\end{tabular}

Note:The figures do not always round up to 3866 due to missing information

* Sterilized women were excluded from this variable

BDHS: Bangladesh Demographic and Health Survey 
15.2 \pm 2.5 years, and $2.7 \pm 1.8$ births per woman, respectively. Twenty-eight percent had no formal education, $40 \%$ had secondary or higher education, and $84 \%$ were married before age 18 -the minimum legal age at first marriage for women in Bangladesh. The vast majority of the respondents were Muslims. Of the most recent births, roughly $32 \%$ were the first pregnancy, $25 \%$ were second, $17 \%$ were third and the rest were fourth or higher order pregnancy. Fifty-two percent of the women discussed FP with their husbands. With regard to wealth index, $51 \%$ were poor and $28 \%$ were rich. Although $80 \%$ had ever used any modern method, the current use rate of modern methods was $49 \%$. Of the respondents, $70.0 \%$ reported that their most recent pregnancy was planned, $14.3 \%$ reported that it was mistimed and $15.7 \%$ reported it was unwanted.

\section{Trends of unintended pregnancy}

Figure 1 shows the trends of unintended pregnancy at the national level in Bangladesh as obtained from the last five BDHSs conducted during 1993-2007. The figures revealed fluctuations in the rate of unintended pregnancy over this period. When comparing the period 1993-1994 to 2007, a decrease from 33 to 29\% can be observed, and there was a consistent decrease from 1999-2000 to 2007.

\section{Pregnancy intention status}

Table II shows the prevalence of unintended pregnancy by selected background characteristics of the women.

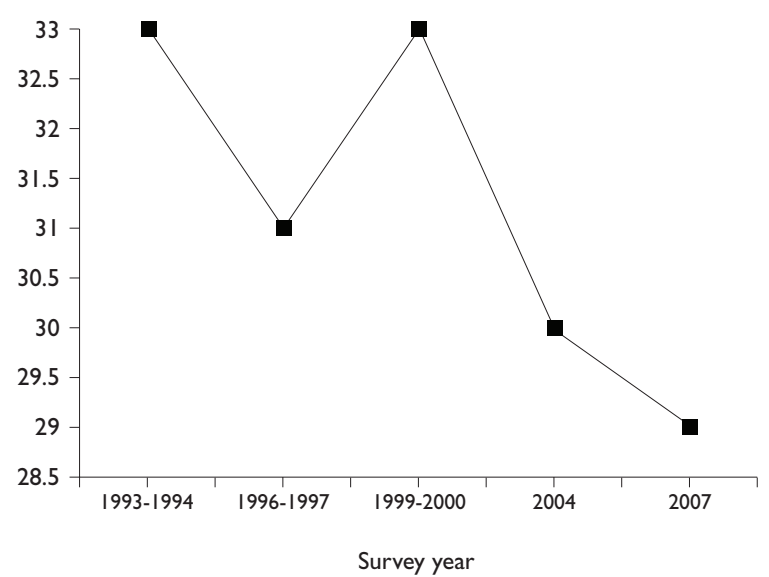

FIGURE I:TRENDS OF UNWANTED PREGNANCY IN BANGLADESH DURING 1993-2007, BDHS: Bangladesh DemographIC and Health Survey, 2007
Overall, $30 \%$ of the women reported that their most recent pregnancy had been unintended. Unintended pregnancy varied significantly by all selected variables. The incidence of unintended pregnancy increased with age. The oldest women were more likely to report to have had unintended pregnancy than the adolescents $(60.1 \%$ vs. $22.5 \%$ ). Unintended pregnancy differed by $10.4 \%$ between women with secondary or higher education $(25.4 \%)$ and those who had no formal education (35.8\%). Unplanned pregnancy was higher among women who were married before age 18 than those who got marriage at age 18 and above (30.5\% vs. $27.3 \%)$.

Muslim women, as compared to non-Muslim, had a higher incidence of unintended pregnancy (30.9\% vs. 20.3\%). Pregnancy order showed a positive association with intention status, with the prevalence of unintended pregnancy being lower among women who discussed FP with their husbands than those who never discussed it $(28.4 \%$ vs. $31.1 \%)$. The incidence of unintended pregnancy was lower in the Rajshahi division and higher in Barisal division. Wealth index showed an inverse association with unintended pregnancy. Reporting of unintended pregnancy was more common among contraceptive users than non-users. Notably, 30.1\% of the current pregnancies were mistimed among the adolescents. The corresponding figure for the poor (combining the poorest and the poor) was 21.1\% (data not shown).

\section{Multivariate analysis}

Table III and Table IV show the results of logistic regression analyses. The results of multivariate logistic regression were almost the same for all the covariates in the two separate models. In both models, women's education, age at marriage, inter-spousal communication about FP and current use of FP methods appeared to have insignificant effects on unintended pregnancy when other variables were controlled, whereas pregnancy order, age, religion, ever use of FP methods, region and wealth index were significantly associated with pregnancy intention status.

Age was positively related to unintended pregnancy, that is, the higher the age the higher was the risk of unintended pregnancy. Non-Muslim women were $50.7 \%$ (95\% CI $=0.38-0.67)$ less likely to report their most recent pregnancy as unintended. Risk of unintended pregnancy for women from the Khulna and Rajshahi divisions was less than that for women from the Barisal division. Women from richer and richest families were $25.4 \%$ (95\% CI $=0.60-0.93$ ) and $37.1 \%$ (95\% CI=0.47-0.84) less likely to report their most recent pregnancy as unplanned, respectively. 
Table II

Percentage distribution of Women by intention status of most Recent Pregnancy AND SELECTED SOCIOECONOMIC CHARACTERISTICS, BDHS, 2007

Characteristics

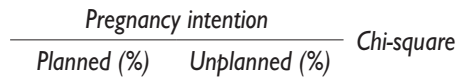

Age group

\begin{tabular}{ccc} 
Age group & & \\
\hline $15-19$ & $519(77.5)$ & $151(22.5)$ \\
\hline $20-24$ & $982(76.1)$ & $309(23.9)$ \\
\hline $25-29$ & $650(69.0)$ & $292(31.0)$ \\
\hline $30-34$ & $353(64.3)$ & $196(35.5)$ \\
\hline $35-39$ & $150(52.5)$ & $136(47.5)$ \\
\hline $40-49$ & $50(39.9)$ & $76(60.1)$
\end{tabular}

Maternal education

$33.0^{*}$

\begin{tabular}{lcc} 
No education & $692(64.2)$ & $385(35.8)$ \\
\hline Primary & $845(69.2)$ & $377(30.8)$ \\
\hline Secondary or more & $1168(74.6)$ & $398(25.4)$
\end{tabular}

Age at marriage

\begin{tabular}{lcc}
$<18$ years & $2245(69.5)$ & $987(30.5)$ \\
\hline 18 or more years & $460(72.7)$ & $173(27.3)$
\end{tabular}

Religion

\begin{tabular}{lrr} 
Religion & & $16.5^{*}$ \\
\hline Islam & $2435(69.1)$ & $3526(30.9)$ \\
\hline Others & $270(79.7)$ & $338(20.3)$
\end{tabular}

Birth order

\begin{tabular}{lcc}
\hline First & $1036(85.0)$ & $182(15.0)$ \\
\hline Second & $716(72.3)$ & $274(27.7)$ \\
\hline Third & $447(68.9)$ & $202(31.1)$ \\
\hline Fourth or more & $506(50.2)$ & $502(49.8)$
\end{tabular}

Discussed family planning

\begin{tabular}{lll}
\hline No & $1247(68.9)$ & $563(31.1)$ \\
\hline Yes & $1407(71.6)$ & $558(28.4)$
\end{tabular}

Note: ${ }^{*} p<0.001, \pm p<0.05,{ }^{\S} p<0.10$

Source: BDHS: Bangladesh Demographic and Health Survey 2007
Characteristics

$\frac{\text { Pregnancy intention }}{\text { Planned (\%) } \quad \text { Unplanned (\%) }}$ Chi-square

Administrative regions

$18.9^{*}$

\begin{tabular}{lll} 
Barisal & $178(66.0)$ & $92(34.0)$ \\
\hline Chittagong & $542(67.4)$ & $261(32.6)$ \\
\hline Dhaka & $737(68.3)$ & $342(31.7)$ \\
\hline Khulna & $304(74.9)$ & $102(25.1)$ \\
\hline Rajshahi & $713(74.0)$ & $251(26.0)$ \\
\hline Sylhet & $232(67.5)$ & $112(32.5)$
\end{tabular}

Wealth index

$19.0^{*}$

\begin{tabular}{lcc}
\hline Poorest & $678(67.4)$ & $328(32.6)$ \\
\hline Poor & $646(67.7)$ & $308(32.3)$ \\
\hline Middle & $559(69.2)$ & $250(30.8)$ \\
\hline Richer & $565(74.4)$ & $195(25.6)$ \\
\hline Richest & $257(76.2)$ & $80(23.8)$
\end{tabular}

Ever used family planning method

$22.0^{*}$

\begin{tabular}{lrr}
\hline Never & $499(77.7)$ & $143(22.3)$ \\
\hline Only traditional & $95(66.9)$ & $47(33.1)$ \\
\hline Only modern & $2111(68.5)$ & $969(31.5)$
\end{tabular}

Currently using family planning method

$7.2^{*}$

\begin{tabular}{lrr}
\hline No & $1219(71.3)$ & $491(28.7)$ \\
\hline Only traditional & $153(63.1)$ & $90(36.9)$ \\
\hline Only modern & $1332(69.7)$ & $579(30.3)$
\end{tabular}

Total

$2705(70.0) \quad 1159(30.0)$
Women who ever used traditional methods and modern methods were $80.6 \%$ (95\% CI $=1.20-2.72)$ and 92.0\% (95\% CI=1.54-2.39) more likely to view their most recent pregnancy as unplanned, respectively. In addition, Table IV shows that the higher the pregnancy order the higher the risk of unplanned pregnancy. For instance, the likelihood of unintended pregnancy for women whose most recent pregnancy was reported as second was 2.09 times (95\% CI=1.69-2.59) that of those reporting it as first order, for those reporting third order 
Table III

Multivariate logistic Regression anAlysis SHOWING THE ODDS RATIOS WITH 95\% CONFIDENCE INTERVAL OF UNPLANNED PREGNANCY AMONG RURAL WOMEN IN BANGLADESH, BY SELECTED BACKGROUND CHARACTERISTICS, BDHS, 2007

\begin{tabular}{|c|c|c|c|c|c|}
\hline \multirow{2}{*}{ Characteristics } & \multirow{2}{*}{$\beta$} & \multirow{2}{*}{$S E$} & \multirow{2}{*}{$\begin{array}{c}\operatorname{Exp}(\beta) \\
(O R)\end{array}$} & \multicolumn{2}{|c|}{$95 \% \mathrm{Cl}$} \\
\hline & & & & Lower & Upper \\
\hline \multicolumn{6}{|l|}{ Age group } \\
\hline $15-19$ & Reference & - & - & - & - \\
\hline $20-24$ & 0.048 & 0.115 & 1.049 & 0.837 & 1.314 \\
\hline $25-29$ & 0.381 & 0.119 & $1.463^{*}$ & 1.159 & 1.848 \\
\hline $30-34$ & 0.586 & 0.131 & $1.797^{*}$ & 1.390 & 2.325 \\
\hline $35-39$ & 1.058 & 0.153 & $2.881^{*}$ & 2.133 & 3.892 \\
\hline-44 & 1.605 & 0.208 & $4.980^{*}$ & 3.312 & 7.488 \\
\hline
\end{tabular}

\begin{tabular}{lccccc}
$\begin{array}{l}\text { Religion } \\
\text { Islam }\end{array}$ & Reference & - & - & - & - \\
\hline Others & -0.667 & 0.145 & $0.513^{*}$ & 0.386 & 0.682
\end{tabular}

Administrative regions

\begin{tabular}{lccccc} 
Barisal & Reference & - & - & - & - \\
\hline Chittagong & 0.149 & 0.156 & $\mathrm{I} .161$ & 0.855 & 1.576 \\
\hline Dhaka & -0.069 & 0.148 & 0.934 & 0.698 & 1.248 \\
\hline Khulna & -0.303 & 0.177 & $0.738 \S$ & 0.522 & 1.045 \\
\hline Rajshahi & -0.317 & 0.152 & $0.729 \S$ & 0.541 & 0.981 \\
\hline Sylhet & 0.180 & 0.185 & 1.197 & 0.833 & 1.720
\end{tabular}

Wealth index

\begin{tabular}{lccccc} 
Poorest & Reference & - & - & - & - \\
\hline Poor & 0.018 & 0.101 & 1.018 & 0.836 & 1.240 \\
\hline Middle & -0.029 & 0.107 & 0.971 & 0.788 & 1.198 \\
\hline Richer & -0.294 & 0.113 & $0.746^{\ddagger}$ & 0.598 & 0.930 \\
\hline Richest & -0.463 & 0.150 & $0.629^{*}$ & 0.469 & 0.845
\end{tabular}

Ever used family planning method

\begin{tabular}{lccccc} 
Never & Reference & - & - & - & - \\
\hline Only traditional & 0.591 & 0.210 & $1.806^{*}$ & 1.197 & 2.724 \\
\hline Only modern & 0.653 & 0.112 & $1.920^{*}$ & $1.54 \mathrm{I}$ & 2.393
\end{tabular}

Note: ${ }^{*} p<0.001 ;{ }^{\ddagger} p<0.01, \S p<0.05$

BDHS: Bangladesh Demographic and Health Survey

it was 2.49 times (95\% CI=1.97-3.14) higher, and for fourth or higher order it was 5.32 times $(95 \%$ CI=4.316.56) higher.

\section{Discussion}

This study examined the prevalence and socioeconomic correlates of unintended pregnancy among rural women
Table IV

MultiVARIATE LOGISTIC REgRESSION ANALYSIS SHOWING THE ODDS RATIOS WITH 95\% CONFIDENCE INTERVAL OF UNPLANNED PREGNANCY AMONG RURAL WOMEN IN BANGLADESH, BY BIRTH ORDER OF CHILD*, BDHS, 2007

\begin{tabular}{|c|c|c|c|c|c|}
\hline \multirow{2}{*}{ Birth order } & \multirow{2}{*}{$\beta$} & \multirow{2}{*}{ SE } & \multirow{2}{*}{$\operatorname{Exp}(\beta)$} & \multicolumn{2}{|c|}{$95 \% \mathrm{Cl}$} \\
\hline & & & & Lower & Upper \\
\hline First & Reference & - & - & - & - \\
\hline Second & 0.738 & 0.108 & $2.092^{\ddagger}$ & 1.691 & 2.587 \\
\hline Third & 0.912 & 0.119 & $2.489 \ddagger$ & 1.973 & 3.140 \\
\hline Fourth+ & $1.67 \mid$ & 0.107 & $5.315^{\ddagger}$ & 4.308 & 6.557 \\
\hline \multicolumn{6}{|c|}{$\begin{aligned} \text { Note: } & * \text { adjusted for other variables except for age } \\
& \ddagger p<0.001\end{aligned}$} \\
\hline \multicolumn{6}{|c|}{ BDHS: Bangladesh Demographic and Health Survey } \\
\hline
\end{tabular}

in Bangladesh. Findings reveal that, overall, $30.0 \%$ of the most recent pregnancies were unintended. Nonetheless, it is likely that the reported incidence of unintended pregnancy was underreported by Bangladeshi rural women. This is because some women are unwilling to report having had an unwanted pregnancy. ${ }^{20}$ Studies conducted elsewhere showed that the prevalence of unintended pregnancy was $38.4 \%$ in Ecuador ${ }^{5}$ during $1992-1994,36.0 \%$ in Guatemala ${ }^{16}$ during 2002, 28.0\% in Nigeria $^{20}$ during 2002-2003, 41.0\% in Nepal ${ }^{21}$ during 2001, and 40.0\% in Vietnam ${ }^{22}$ during 1994-1997. In a hospital-based study, the reported rate of unintended pregnancy was $33.0 \%$ in Bangladesh and $44.0 \%$ in the Philippines. ${ }^{30}$ Our findings suggest that the prevalence of unintended pregnancy among Bangladeshi rural women was higher than that in Nigeria and lower than that in the Philippines, Guatemala, Nepal, Ecuador, and Vietnam.

Our study suggests that millions of Bangladeshi rural women have confronted unwanted pregnancy at some point in their lives. Our findings show that age, religion, administrative region, wealth index, and ever use of any contraceptive method were significantly associated with unintended pregnancy, while pregnancy order was the most single determinant of unplanned pregnancy. And though studies conducted elsewhere showed that unplanned pregnancies happen for many reasons -including religious and cultural beliefs-contraceptive failure is shown to be the most important factor. ${ }^{23}$ Therefore, the relationship between the use of modern methods and increased risk of unintended pregnancy suggests an urgent need for further research.

Findings indicate that particular groups of women had an increased risk of unplanned pregnancies, thus the urgent need for quality family planning services in 
rural Bangladesh. For example, the significant difference in the pregnancy intention status by region suggests the need for expanded and improved family planning services among women of Barisal, Chittagong and Sylhet, as these divisions are distinctive in terms of their geographical nature and cultural variations among the inhabitants. According to the 2007 BDHS, women from these three divisions had higher levels of fertility and a lower use rate of contraceptive methods as compared to other divisions. ${ }^{13}$ Targeting these areas and population subgroups with expanded FP programs may reduce the incidence of unintended pregnancy as well as fertility.

As was expected, older and Muslim women were at increased risk to have experienced an unintended pregnancy as compared to younger and non-Muslim women. It is evident that Muslim women as compared to their non-Muslim peers are less likely to use modern methods due to their traditional beliefs and cultural norms, while older women are more reluctant to use modern methods as compared to their younger counterparts, resulting in a higher risk of unintended pregnancy among the former. ${ }^{13}$ Early initiation of sexual intercourse, (early age at marriage) is another important aspect of unplanned pregnancy. Bangladesh has a long tradition of early marriage and has one of the lowest mean ages at first marriage for females around the world. This results in women having marriages with longer duration and, hence, increases the risk of frequent and unintended pregnancies. The above findings are consistent with many studies conducted elsewhere. ${ }^{21,24}$

Women's education-an important factor in explaining the fertility and fertility behavior of women- had no significant effect on unintended pregnancy in our study. This finding is contradictory to those of other studies ${ }^{25,26}$ and consistent with studies conducted in Nepal, Palestine, Japan and Indonesia. ${ }^{21,24,27,28}$ The possible reasons for the lack of association between women's education and unintended pregnancy may be the low variability of education in the sample of women and lower participation in formal jobs. However, the fact is that this relationship persists after controlling for fertility preference and family planning practice, suggesting that the relationship between education and unplanned fertility may be quite complex and not fully explainable by this factor. ${ }^{25}$

Consistent with earlier studies, ${ }^{25.29}$ pregnancy order appeared as the most single significant determinant of unintended pregnancy. The increased risk of unintended pregnancy among women with more than two living children could be a sign of discontinuity or experiencing difficulty with using contraceptive methods. ${ }^{5,29}$ Somewhat surprisingly, the difference between poor and middle class women in likelihood of unintended pregnancy was insignificant. These findings suggest that poor and middle class women were similar to one another and unable to afford family planning services, unlike rich women, ${ }^{5}$ and therefore less able to control their fertility.

The positive association between unplanned births and contraceptive use reflects the tendency to adopt contraception after an unwanted pregnancy to avoid a repeat occurrence. ${ }^{25}$ However, the association between unplanned births and ever use of contraceptives is of particular concern and has important implications for the family planning program in Bangladesh. The higher probability of unplanned births among women who had ever used modern family planning methods suggests a possibility of problems with contraceptive use effectiveness, including contraceptive discontinuation or failure. ${ }^{5}$ These findings are also consistent with earlier studies. ${ }^{21,25}$

There are several limitations to be considered when interpreting these findings. First, the study used cross-sectional survey data that looked retrospectively at women's pregnancy intention status. Thus, the study results should be cautiously interpreted in view of the limitations of the cross-sectional design, which limits a study's ability to draw causal inferences. Second, since retrospective information generally suffers from underreporting, the analysis can only provide evidence of statistical associations between those items and the experience of unintended pregnancy; it cannot show cause-effect relationships. ${ }^{21}$ Despite this, the strength of the study is that it dealt with nationally representative sample survey data that are mostly used in health and demographic related research.

The results indicate that unintended pregnancy is a major obstacle to reduce fertility to replacement level, which is a priority for population policy in Bangladesh. Policymakers and health service providers can benefit from the findings of this study to formulate suitable programs. In conclusion, programs should aim to reduce unintended pregnancy by focusing on all those factors identified, so as to decrease fertility and infant and maternal mortality, as well as the need for abortion. Intervention programs concerning reproductive health and services should be undertaken and awareness should be created as to the use of effective contraceptive methods to avoid unintended pregnancy, not only to reduce fertility but also to reduce adverse health outcomes for rural women in Bangladesh.

Declaration of conflicts of interest: The authors declare that they have no conflict of interests. 


\section{References}

I. Santelli JS, Rochat R, Hatfield-Timajchy K, Gilbert B, Curtis K, Cabral R. The measurement and meaning of unintended pregnancy. Perspect Sex Reprod Health 2003; 35:94-101.

2. Smith R,Ashford L, Gribble J, Clifton G. Family planning saves lives. Washington DC: Population Reference Bureau, 2009.

3. World Health Organization (WHO). Maternal Mortality in 2006 : Estimates Developed by WHO, UNICEF, UNFPA and the World Bank. Geneva:WHO, 2008.

4. Casterline JB, El-Zanatay F, El-Zeni LO. Unmet need and unintended fertility: Longitudinal evidence from Upper Egypt. Int Fam Plann Perspect 2003; 29:158-66.

5. Eggleston E. Determinants of unintended pregnancy among women in Ecuador. Int Fam Plann Perspect 1999; 25:27-33.

6. Glasier A, Gulmezoglu AM, Schmid GP, Moreno CG, Van Look PF. Sexual and reproductive health: a matter of life and death. Lancet 2006; 368:1595-1607.

7. Langer A. Unwanted pregnancy: impact on health and society in Latin America and the Caribbean. Rev Panam Salud Publica 2002; 1 I:192-204. 8. Karim, DRA. Reproductive health, including Adolescent reproductive health: progress and challenges in Asia and the Pacific.Asia-Pac Popul J 2009; 24: 153-196.

9. Reardon DC, Cougle JR. Depression and unintended pregnancy in the national longitudinal survey of youth: a cohort study. BMJ 2002; 324:15I-I52. 10. Russo NF, Denious JE.Violence in the lives of women having abortions: implications for practice and public policy. Prof Psychol: Res Pract 200I; 32:142-150.

II. Gipson JD, Koenig MA, Hindin MJ.The effects of unintended pregnancy on infant, child, and parental health: a review of the literature. Stud Fam Plann 2008; 39:18-38.

12. Klima CS. Unintended pregnancy: consequences and solutions for a worldwide problem. J Nurse Midwifery 1998; 43:483-49I.

13. National Institute of Population Research and Training (NIPORT), Mitra and Associates, and Macro International. Bangladesh Demographic and Health Survey 2007. Dhaka, Bangladesh and Calverton, Maryland, USA: NIPORT, Mitra and Associates, and Macro International, 2009.

14. National Institute of Population Research and Training (NIPORT),

ORC Macro, Johns Hopkins University and ICDDR,B. 2003. Bangladesh Maternal Health Services and Maternal Mortality Survey 200I. Dhaka, Bangladesh and Calverton, Maryland (USA): NIPORT, ORC Macro, Johns Hopkins University, and ICDDR,B, 2003.

15. Chowdhury ME, Botlero R, Koblinsky M, Saha SK, Dieltiens G, Ronsmans C. Determinants of reduction in maternal mortality in Matlab, Bangladesh: a 30- year cohort study. Lancet 2007; 370:1320-1328.
16. Barden-O'Fallon JL, Speizer IS, White JS. Association between contraceptive discontinuation and pregnancy intentions in Guatemala. Rev Panam Salud Publica 2008; 23:410-4I7.

17. Chandra A, Martinez GM, Mosher WD, Abma JC, Jones J. Fertility, family planning, and reproductive health of U.S. women: Data from the 2002 National Survey of Family Growth.Vital and Health Statistics, Series 23, Number 25. Hyattsville, Maryland: National Center for Health Statistics, US Department of Health and Human Services, 2005.

18. Blanc AK, Curtis SL, Croft TN. Monitoring contraceptive continuation: links to fertility outcomes and quality of care. Stud Fam Plann 2002; 33:127-| 40.

19. Westoff CF, Ryder NB. The predictive validity of reproductive intentions. Demography 1977; I4:43 I-453.

20. Sedgh G, Bankole A, Oye-Adeniran B,Adewole IF, Singh S, Hussain R. Unwanted pregnancy and associated factors among Nigerian women. Int Fam Plann Perspect 2006; 32:175-I84.

21.Adhikari R, Soonthorndhada K, Prasartkul P. Correlates of unintended pregnancy among currently pregnant married women in Nepal. BMC Int Health Hum Rights 2009; 9:17.

22. Le LC, Magnani R, Rice J, Speizer I, Bertrand W. Reassessing the level of unintended pregnancy and its correlates in Vietnam. Stud Fam Plann 2004; 35:15-26.

23. Shokravi AF, Chapman H, Peyman N.A comparison study: Risk factors of unplanned pregnancies in a group of Iranian and New Zealander women. Eur J Sci Res 2009; 26: 108-121.

24. Giacaman R,Abu-Rmeileh NME, Mataria A,Wick L. Palestinian women's pregnancy intentions: analysis and critique of the Demographic and Health Survey 2004. Health Policy 2008; 85:83-93.

25. Magadi MA. Unplanned childbearing in Kenya: the sociodemographic correlates and the extent of repeatability among women. Soc Sci Med 2003; $56: 167-78$

26. Pulley LV, Klerman LV,Tang H, Baker BA.The extent of pregnancy mistiming and its association with maternal characteristics and behaviors and pregnancy outcomes. Perspect Sex Reprod Health 2002; 34:206-2II. 27. Goto A, Yasumura S, Reich MR, Fukao A. Factors associated with unintended pregnancy in Yamagata, Japan. Soc Sci Med 2002; 54:1065-1079. 28. Weller RH, Sly D, Sukamdi A, and Ekawati R. The wantedness status of births in Indonesia. Demographic and Health Surveys World Conference, Calverton MD: Macro International Inc., 1991.

29. Goicolea I, and Sebastian MS. Unintended pregnancy in the Amazon basin of Ecuador: a multilevel analysis. Int J Equity Health 2010; 9:14. 30. Singh S, Cavigon JV, Hossain A, Kamal H, Perez AE. Estimating the level of abortion in the Philippines and Bangladesh. Int Fam Plann Perspect 1997; 23:100-107 \& 144. 